\title{
Impacts of Organizational Culture
}

\author{
Manuela Morelli ${ }^{1 *}$, Manke Wang ${ }^{2}$ \\ ${ }^{1}$ PhD in Sociology, a post-graduate in Human Resources and Communication and a Master Degree in \\ Psychology. \\ ${ }^{2}$ Associate Welfare Officer at the International telecommunication Union (ITU), a specialized agency of the \\ United Nations.
}

*Corresponding Author: Manuela Morelli, PhD in Sociology, a post-graduate in Human Resources and Communication and a Master Degree in Psychology.

\begin{abstract}
The organizational culture as a shared description of an organization from within helps to create a unique social and cultural environment within the group, which later influences how people normally behave and think, and direct them into a sense of collective values, beliefs and principles, such as the group's values, norms, beliefs, visions, and styles (Schrodt, 2002). Because of its collaborative and collective patterns, organizational culture plays a huge role in organizational management from individual level to overall organizational level. For instance, during the early stage of a company, employees mostly would like to have higher and stronger motivations even without any external incentives; or on the other hand, recreating an organization culture would also help on the organization's both internal and external development.
\end{abstract}

The objective of this paper is to introduce the definition of organizational culture, identify its impacts on companies from individual employee level to overall organizational level.

Keywords: Organizational culture, motivations, employee engagement, leadership, Change management, International Organizations.

\section{The Definition of the Organizational Culture}

The organizational culture is defined as "the collaborative process of creating shared awareness and understanding out of different individuals' to help and orient its members to "reality" in ways that provide a basis for alignment of purpose and shared action (Watkins, 2013, p. 2-3). Schrodt (2002), for example, describes that "the pattern of such collective behaviors and assumptions that are taught to new organizational members as a way of perceiving and, even thinking and feeling.'In all, this jointly shared description turns to create a unique social and cultural environment within the group, which later, if it succeeds, manages to direct what an individual employee normally behaves based on a sense of collective values, beliefs and principles, as the so-called group's styles, visions, and norms.

What's more, the organizational cultures provide not only a shared view of "what is" but also of "why is". In this view, an organizational culture is about "the story" in which people in the organization are embedded (Watkins, 2013, p. 3), which means an organizational culture can be learned and shared to eventually guide employees' decision makings and daily behaviors. For example, in the beginning a new-arriving member of an organization usually will, besides be introduced the values, visions, and norms of the company, be required to participate in some internal induction orientations, namely team-building activities, which they would have the chance to personally experience why the current organizational culture is. Therefore, an organizational culture is dynamic and shifting constantly in response to external and internal changes, and never monolithic, including many sub-cultures that drive internal variations in the culture of business functions and units (Watkins, 2013, p. 4). For instance, the organizational culture forms a social norm or an acceptable group conduct inside the organization, which always rewards a "right" doing, and sanctions a "wrong" thinking and behaving. 
For instance, the evolution of organization's induction programme can be considered as the best example to display the influence of the organizational culture. In the past the induction programme was generally held to ensure new employees to familiarize with their position and job requirements. On the contrary, nowadays it is emphasized to define the organizational approaches during the supportive introductory stage for new employees to settle quickly into their job (Dragomiroiu, Hurloiu, \& Mihai, 2014).

\section{The Organizational CUlture's EFFeCt On Individual-LeVEL}

Watkins (2013) once compared the organizational culture to the human immune system, controlling the protection system and preventing "wrong thinking" and "wrong people" from entering the organization in the first place. For example, a culture within teams or organizations constructs a social control system based on shared norms and values in order to show how a shared normative order or culture can influence members' focus of attention, shape interpretations of events, and guide attitudes and behavior (O'Reilly, \& Chatman, 1996). Under this social control system, a mutual agreement is well accepted, and any employees who do not appreciate organizational values or share a similar belief will be automatically ruled out.

Furthermore, under the social influence of an organizational norm, a culture also directs the behaviors and decision making abilities of employees in their daily workplace. And this cultural influence is grounded in strategy supportive values, practices and behavioral norms adds to the power and effectiveness of a company's strategy execution effort (Muthoni, 2012, p. 11-12). For example, new technology companies, such as Apple or Google, which highly appreciate technological innovation, would prefera technological orientated strategies and focus on exhibiting creativity, embracing change and talents seeking. Generally speaking, apart from the impacts on individual level to employees, organizational cultures also find its influences everywhere in an organization, from structure to strategic implementations. For instance, Towers (2006) used Google as the typical example of a hugely successful firm with a very strong culture. The fruit of this organizational culture are motivated employees who live the Google brand calling themselves "Goolgers".

\section{The ORganizational CULTURE'S EFFECT ON ORGANIZATIONAL-LEVEL}

In addition, in the organization-level, there is a correlative relationship between the organizational culture and the communication: communication creates and recreates organizational reality, on the other hand, communication in an organization is also constrained by the prior reality and also shapes the existing reality (Keyton, 2011, p. 44). For instance, Brown and Starkey (1994) presented a theoretical and empirical examination of the effects of culture on communication and information in organizations. In particular, they found out that attitudes to communication and information that had their roots in a dominant organizational culture. On the other way around, communication helps individuals to coordinate their activities to achieve goals. Moreover, in a broader picture, the organizational culture also generates its impact on organizational structure both through its design and its implementation. The culture creates a frame of reference in which the organization management's considerations and reasoning circulate in the process of decision-making concerning the organizational structure model (Janićijević, 2013, p. 39-40). In order to good accord with its organizational culture, the top-level management always selects a structure model, which is able to best interpret and represent their company's culture. For instance, a company with a strong dictatorship culture would not select a loose and decentralized structure model. Particularly, researchers conducted a study to measure organizational capabilities to horizontal strategy implementation (Verma, Sharma, \& Chen, 2020). The data were drawn from a sample survey of 122 firms in India, which identifies a significant influence of leadership styles and interactive control system on horizontal strategy implementation, and organizational capabilities that play a critical role in the implementation of horizontal strategy. 


\section{The Organizational Culture's Overall EfFects}

As a result, it is not difficult to conclude that this shared values and beliefs has the further influences on employees' motivation, satisfaction, and commitments as to assemble people together, making them have a strong connection with each other and the organization. Individuals are motivated to "make sense" of their environment and understand why things happen (Heider, 2013), which allows them to establish a strong emotional belonging in the employees. Consequently, with the motivation increasing, employees will also feel a stronger commitment and satisfaction. For example, Pranita (2018) selected a sample of 60 respondents to examine the influence of motivation and organizational commitment to job satisfaction and employee performance. The results showed a positive influence between motivation to job satisfaction; a positive influence between the organizational commitment on job satisfaction. Therefore, it is clear to say that organizational cultures have a great impact on employees' individual behaviors and emotions: the stronger an organizational culture is, the employees feel more motivation, commitment, and satisfactions. Eventually all these positive feelings combine to create a very strong and inevitable sense of employee belongingness, which increases an employee's willingness to comply, cooperate, and help others in the organization according to its rules. A workplace functions better as a collective whole.

Now with the help of this conclusion, we can manage to understand why gradually motivating public employees is becoming a nearly impossible mission comparing to the private sectors. Particularly, Panagiotis, Alexandros, and George (2014) employed a Competing Values Model to diagnose the organizational culture and to illuminate the relationship of culture and motivation in the organization studied. They found out that the dominant culture type is Hierarchy (Bureaucracy) while motivation level was found to be low, demonstrating a negative association between the two variables. Furthermore, de-motivational employees continue to damage the organizations' innovation and development. Harrison and Baird (2015) studied the cultural change across different types of public sector organizations, and the results show little change having occurred in the culture of other types, specifically government departments and agencies, which continue to lag behind their private sector counterparts in the cultural factors of Outcome Orientation and Innovation.

For example, one of the most well-known but as well discussed organization in the world is the United Nations. These universal values are endorsed by the body's 193 member states and articulated in the UN charter and other documents, which further establish the mission, structure, and functioning of the organization (Clarke, n.d.). Accordingly, the UN's culture is influenced heavily under the political and intergovernmental impacts and structures, and exhibited a characteristic of highly hierarchy system. Second, as the biggest and most authoritative intergovernmental organization, the UN also does not need to worry about any outside competitions in the market or potential bankruptcy after any misconducts.

Therefore, undoubtedly, the UN's organizational cultures lowly has evolved into extremely bureaucracy and inefficiency, which affects a wide variety levels within the organization, such as communication, strategy, and control. For example, due to the huge hierarch, efficient communications among employees within the system disappear; a shared value/vision starts to break down and evolve separately; the top-level directors notice that it becomes harder and harder to communicate and deliver any missions to the field officers, and with a great possibility of losing control in the system. Consequently, here have been many voices that demands a radical and thorough change within the system. For instance, Javan, director in the United Nations System Staff College, summaries the problem that traditionally, the UN treats organizational change as a process that starts at the top and filters down. While this approach seems necessary to ensure proper adherence to new ways of working, it brings with it some challenges. Problems begin to arise when the upper echelons of the UN make decisions that affect the entire system, and do not communicate directly. Neither do they encourage direct participation from staff in decision-making (2017). I would go a step further: since the MDGs became SDGs, the work, the structure and therefore the culture of UN has become less bureaucratic and more results-based. More precisely, the concept of sustainability has nurtured also a culture of accountability. With more attention to results, the culture has become more agile, the work more project-based and the structure more horizontal. Some references and elaboration of this would be great. 
Moreover, a group of researchers conducted a study about the relationship between effectiveness and organizational culture, structure, etc., based on 301 organizations. The results suggest that knowledge management fully mediates the impact of organizational culture on organizational effectiveness, and partially mediates the impact of organizational structure and strategy on organizational effectiveness (Zheng, Yang, \& McLean, 2010). Therefore, we can notice that a deteriorating organizational culture has a huge negative effect on the organization's both internal and external development. In conclusion, some public sectors, especially the United Nations, requires a change in their organizational culture. Because only after accomplishing the change in the culture, an organization could regain the motivation and commitment from its employees, and create a positive foundation for any further organizational changes, namely, a direct and effective leadership, a compatible organizational structure, etc.

In a word, the organizational culture is the "root" for the development of a company, and it plays a fundamental role from employee individual level to the strategic implementation level. Most importantly, a positive organizational culture will help a company to strive and survive during the market competitions. However, a negative or damaging organizational culture will destroy a company from the foundation. Sometimes it has been already too late when people realize the damages and it will not be easy to change the current harmful situation. Therefore, it is critical for people especially top-level managers to pay a great attention on the organizational culture and be aware of its impacts on their organizations.

\section{REFERENCES}

[1] Brown, A. D., \& Starkey, K. (1994). The effect of organizational culture on communication and information. Journal of Management studies, 31(6), 807-828.

[2] Clarke, A. (n.d.). Organizational Culture, System Evolution, and the United Nations of the 21st Century. INSIDER'S VIEW, 127-133. Retrieved March 16, 2019, from https://acun s.org/wpcontent/uploads/2014/02/Organizational-Culture-System-Evolution-and-the-United-Nations-of-the-21stCentury.pdf

[3] Dragomiroiu, R., Hurloiu, I. I., \& Mihai, G. (2014). Induction staff training. Procedia Economics and Finance, 16, 368-373.

[4] Harrison, G. L., \& Baird, K. M. (2015). The organizational culture of public sector organizations in Australia. Australian Journal of Management, 40(4), 613-629.

[5] Heider, F. (2013). The psychology of interpersonal relations. Psychology Press.

[6] Janićijević, N. (2013). THE MUTUAL IMPACT OF ORGANIZATIONAL CULTURE AND STRUCTURE. Ekonomski Anali/Economic Annals, 58(198), 39-40.

[7] Javan, J. (2017, April 27). Changing the organizational culture of the UN: A bottom up approach matters! Retrieved February 15, 2019, from https://www.unssc.org/news-and-insights/blog/changing-organization al-culture-un-bottom-approach-matters/

[8] Keyton, J. (2011). Communication and organizational culture: A key to understanding work experiences. Sage, 44.

[9] Muthoni, E. U. N. I. C. E. (2012). Effects of organizational culture on strategy implementation in commercial banks in Kenya. Unpublished MBA project, School of Business, University of Nairobi, 11-12.

[10] O'Reilly, C. A., \& Chatman, J. A. (1996). Culture as social control: Corporations, cults, and commitment.

[11] Panagiotis, M., Alexandros, S., \& George, P. (2014). Organizational culture and motivation in the public sector. the case of the city of zografou. Procedia Economics and Finance, 14, 415-424.

[12] Pranita, F. M. (2018). Influence Of Motivation And Organizational Commitment On Work Satisfaction And Employee Performance. Proceedings of the ICECRS, 1(2).

[13] Schrodt, P. (2002). The relationship between organizational identification and organizational culture: Employee perceptions of culture and identification in a retail sales organization. Communication studies, 53(2), 189-202.

[14] Towers, D. (2006). An investigation into whether organisational culture is directly linked to motivation and performance through looking at Google Inc. British Journal of Social of Psychology, 42, 87-106.

[15] Verma, P., Sharma, R. R. K., \& Chen, L. H. (2020). Measuring organizational capabilities to horizontal strategy implementation for conglomerates. Business Strategy \& Development, 3(1), 64-76.

[16] Watkins, M. (2013). What is organizational culture? And why should we care. Harvard Business Review, $1-6$. 
[17] Zheng, W., Yang, B., \& McLean, G. N. (2010). Linking organizational culture, structure, strategy, and organizational effectiveness: Mediating role of knowledge management. Journal of Business research, 63(7), 763-771.

Citation: Manuela Morelli, Manke Wang. "Impacts of Organizational Culture" International Journal of Managerial Studies and Research (IJMSR), vol 8, no. 7, 2020, pp. 95-99. doi: http:/dx.doi.org/10.20431/23490349.0807012.

Copyright: () 2020 Authors. This is an open-access article distributed under the terms of the Creative Commons Attribution License, which permits unrestricted use, distribution, and reproduction in any medium, provided the original author and source are credited. 